\title{
Mapeamento cognitivo e Balanced Scorecard na gestão estratégica de resíduos sólidos urbanos
}

\section{Strategic solid waste management using Balanced Scorecard}

\author{
Ricardo Gabbay de Souza ${ }^{1}$ \\ João Sérgio Cordeiro²
}

\begin{abstract}
Resumo: Os serviços públicos estão situados num ambiente bastante dinâmico, exigindo de seus gestores uma boa percepção dos fatores internos e externos que determinam a realidade dos sistemas. Particularmente, na gestão de resíduos sólidos urbanos no Brasil, este universo se caracteriza por pressões e limitações políticas, influência dos padrões de produção e consumo da sociedade e inadequações ambientais. Para um desenvolvimento sustentável nestes sistemas, é necessário que os diversos aspectos se alinhem aos princípios da sustentabilidade, definindo uma estratégia de ação. Atualmente, uma ferramenta bastante utilizada para a gestão da estratégia é o Balanced Scorecard, cujas principais vantagens funcionais são a análise do posicionamento organizacional por múltiplas perspectivas, extrapolando o âmbito estritamente financeiro e operacional e a construção de um mapa estratégico que comunica visualmente a hierarquia das consecuções pretendidas para a organização. Este trabalho procurou analisar o comportamento deste método quando aplicado à gestão de resíduos sólidos urbanos e utilizou como objeto de estudo um Consórcio fictício entre Araraquara e São Carlos (SP). Os resultados apontam para uma boa aplicabilidade desta ferramenta, e, apesar das poucas adaptações, se manteve a hierarquia estratégica entre os aspectos de aprendizado e crescimento, processos internos, da sociedade e institucional.
\end{abstract}

Palavras-chave: Gestão de resíduos sólidos urbanos. Desenvolvimento sustentável. Estratégia. Balanced Scorecard. Mapeamento cognitivo.

\begin{abstract}
The public sector services are inserted in a very dynamic environment forcing their administrators to focus on internal and external factors that determine the systems' reality. Particularly for the solid waste management in Brazil, this universe is defined by political pressures and limitations, influences by population's consuming patterns, and environmental inadequacies. For a sustainable development in these systems, it is necessary an alignment between the several aspects and the sustainability principles developing action strategies. Currently, Balanced Scorecard is a widely used strategic management tool, which main advantages are: the analysis, beyond the strictly financial and operational focus, of organizations' positioning under many perspectives, and the design of a strategy map, which visually communicates the hierarchy of organizations' intended goals. It is also structured. A corporate score card containing the objectives and their related measures, goals, and initiatives is also designed, both at organizational and departmental levels. This research analyses the applicability of this method for the solid waste management in a simulated trust between the cities of Araraquara and São Carlos in the state of São Paulo. This allowed working with more than one strategy, including the system's most probable management function workers. The results indicate a great applicability of the tool, and despite the few adaptations needed, the hierarchal strategy between the aspects of learning, growing, and internal processes, and those of the organization and society were kept
\end{abstract}

Keywords: Solid waste management. Sustainable development. Strategy. Balanced Scorecard. Cognitive mapping.

\section{Introdução}

A gestão pública de resíduos é um sistema que, tradicionalmente, tem recebido uma baixa prioridade estratégica dos Governos nas diversas esferas especialmente as prefeituras, as principais responsáveis por este serviço público, de acordo com a Constituição Federal de 1988. Como consequência, estas entidades não desenvolvem uma percepção ampla da cadeia de relações causais relativa a este sistema, o que se reflete

\footnotetext{
${ }^{1}$ Engenheiro Civil pela Universidade da Amazônia, Mestre em Engenharia Urbana pela Universidade Federal de São Carlos, Doutorando em Engenharia de Produção na Universidade Federal do Rio de Janeiro - Centro de Tecnologia, Bloco I, Sala I-036, Cidade Universitária, Ilha do Fundão, CEP 21945-970, Rio de Janeiro - RJ, E-mail: rgabbay @ pep.ufrj.br

${ }^{2}$ Engenheiro Civil e Doutor em Hidráulica e Saneamento pela Universidade de São Paulo, Professor do curso de Engenharia Civil e do Programa de Pós-Graduação em Engenharia Urbana da Universidade Federal de São Carlos - Rodovia Washington Luis, km 235, CEP 13565-905, São Carlos - SP, E-mail: cordeiro@ power.ufscar.br
}

Recebido em 30/6/2008 — Aceito em 10/7/2010

Suporte financeiro: CAPES 
no cenário atualmente padrão no Brasil: inadequação ambiental da disposição final dos rejeitos, riscos à salubridade e qualidade de vida da população e catadores, com baixo direcionamento e capacitação de recursos, ineficiência na sua aplicação e pouco envolvimento direto da sociedade.

Como resposta a estes fatores, algumas experiências no Brasil apontam a tendência em transferir a gestão do saneamento ambiental para autarquias e consórcios públicos (estes últimos regidos pela Lei Federal $\left.\mathrm{N}^{\circ} 11.107 / 05\right)$, tendência esta que será cada vez mais estimulada, a partir do sancionamento da Política Nacional de Resíduos Sólidos (previsto para 2010, após 21 anos de tramitação do Projeto de Lei). Estas formas de entidades possuem autonomia administrativa e orçamentária, pois constituem entes jurídicos distintos. Os consórcios possuem ainda a vantagem da integração e compartilhamento de experiências, visões e recursos, por se tratarem de uma associação entre governos com criação de uma empresa sustentada por legislação municipal específica. Por outro lado, aumenta sobre as gerências destas formas de entidades as pressões externas, o que exige uma maior capacidade de sistematizar as relações e ações diversas, por parte dos gestores.

O presente trabalho tem como objetivo analisar na gestão de resíduos sólidos urbanos o processo de estruturação da estratégia baseado no Balanced Scorecard, bastante utilizado atualmente principalmente no âmbito das empresas privadas, sendo subsidiado pelo mapeamento cognitivo e os conceitos gerais sobre sustentabilidade. Para tanto, considerou-se um consórcio intermunicipal recentemente estabelecido entre os municípios de Araraquara e São Carlos (SP), com o intuito de verificar o comportamento do processo de concepção de um modelo estratégico de sustentabilidade em uma empresa pública, cuja alta gerência é composta por mais de uma pessoa.

\section{Breve cenário da gestão de resíduos sólidos no Brasil}

A gestão ou gerenciamento de resíduos sólidos compreende a priori todos os processos de administrar a operacionalização das atividades de coleta, tratamento e disposição final de resíduos. No entanto, como em qualquer sistema produtivo, existem outras funções além da operacional que fornecem o suporte e definem o posicionamento deste sistema em seu ambiente.

Como afirma Slack (2002), toda organização possui três funções centrais e outras de apoio (Desenvolvimento, Produção e Marketing), o que não quer dizer que haja necessariamente unidades específicas para cada uma, pois, nas diferentes naturezas das organizações, estes papéis podem ser desempenhados até mesmo por um único indivíduo. As designações destas funções também variam, pois Marketing não é um termo adequado aos serviços públicos, embora sua essência seja a de manter o veículo de comunicação e garantir a satisfação dos clientes.

Desta forma, a alta gerência da gestão de resíduos sólidos está envolvida com o sistema produtivo e igualmente com as áreas de contato e suporte à população, relações com os fornecedores e planejamento e desenvolvimento. As fronteiras do serviço são delimitadas pelas conexões totais de que dispõe com seu ambiente (Quadro 1).

A Associação Nacional dos Sistemas Municipais de Saneamento fez um levantamento de experiências brasileiras nestes serviços públicos (ASSOCIAÇÃO NACIONAL DOS SERVIÇÕS MUNICIPAIS DE SANEAMENTO, 2006), as quais foram analisadas em função de seus alinhamentos aos princípios do desenvolvimento sustentável. De acordo com as experiências que mais se destacaram, é possível esboçar uma provável estrutura organizacional a partir de padrões apresentados:

- Centro de Educação Socioambiental: parceria com universidades, democratização do

Quadro 1. Processos e conexões externas da função operacional da gestão de resíduos.

\begin{tabular}{|c|c|c|}
\hline Processos & Atividades & Conexões \\
\hline Acondicionamento & $\begin{array}{l}\text { Instalação de acondicionadores, separação, } \\
\text { acondicionamento, degradação }\end{array}$ & $\begin{array}{l}\text { População, trabalhadores informais, } \\
\text { intempéries, animais e processos naturais }\end{array}$ \\
\hline Coleta e transporte & $\begin{array}{l}\text { Manuseio, compactação, cumprimento do } \\
\text { trajeto, transferência dos resíduos }\end{array}$ & $\begin{array}{l}\text { Fornecedores (equipamento, combustível, } \\
\text { etc.), trabalhadores formais, meio ambiente, } \\
\text { população, infraestrutura urbana }\end{array}$ \\
\hline Transferência & $\begin{array}{l}\text { Receptação, condução, estocagem, triagem, } \\
\text { carregamento de veículos }\end{array}$ & $\begin{array}{l}\text { Trabalhadores, mercado de recicláveis, } \\
\text { fornecedores }\end{array}$ \\
\hline Tratamento & $\begin{array}{l}\text { Reciclagem, compostagem, tratamento físico, } \\
\text { químico, biológico }\end{array}$ & $\begin{array}{l}\text { Mercado de recicláveis, trabalhadores, } \\
\text { população, meio ambiente }\end{array}$ \\
\hline Disposição final & $\begin{array}{l}\text { Dimensionamento e preparação, receptação, } \\
\text { confinamento, degradação, drenagem, } \\
\text { tratamento de efluentes }\end{array}$ & $\begin{array}{l}\text { Meio ambiente, população, fornecedores, } \\
\text { trabalhadores }\end{array}$ \\
\hline
\end{tabular}

Fonte: Monteiro, et al. (2001) e Tchobanoglous (1993). 
conhecimento técnico, programas de visitação e cursos e oficinas para alunos e professores;

- Desenvolvimento de Recursos humanos: assistência social, saúde e segurança do trabalho, assessoria aos trabalhadores e suas famílias; recrutamento e treinamento;

- Equipe e Laboratório de Qualidade: aferição dos equipamentos, medição dos serviços, definição de sistema de indicadores, benchmarking, capacitação, Certificação ISO 9001;

- Desenvolvimento: modernização dos sistemas, utilização de SIG, integração de políticas e programas com outras ações da administração pública;

- Financeiro: desenvolvimento de banco de dados de preços públicos e de projetos técnicos, realização de pregão e licitações, adequação do sistema tarifário, concessão de isenções e concepção de mecanismos de compensação; busca de financiamentos;

- Jurídico: adequação às leis ambientais e ao Plano Diretor, agilização dos trâmites na Câmara de Vereadores; defesa dos interesses da organização e da sociedade;

- Conselho Consultivo: participação e controle da população; realização de Conferências; elaboração de diagnósticos e planejamento estratégico; e

- Departamento de Comunicação Social e Relações Comunitárias: atendimento ao público, democratização de informações, resposta imediata a solicitações; realização de parcerias e articulação de eventos com a sociedade
(ASSOCIAÇÃO NACIONAL DOS SERVIÇÕS MUNICIPAIS DE SANEAMENTO, 2006).

\subsection{Alguns problemas na gestão de resíduos sólidos brasileira}

Analisando no nível mais operacional e técnico, o tratamento dado no Brasil para seus resíduos sólidos ainda está muito aquém de uma situação adequada. A grande maioria dos materiais ainda é disposta inadequadamente, e as experiências de coleta seletiva ainda são muito pontuais. No entanto, existem ainda outros fatores que também são dignos de preocupação por parte da gestão destes sistemas. O Quadro 2 apresenta alguns exemplos de problemas que estão diretamente relacionados aos resíduos sólidos no país.

A Pesquisa feita pela ASSEMAE (ASSOCIAÇÃO NACIONAL DOS SERVIÇÕS MUNICIPAIS DE SANEAMENTO, 2006) avaliou uma grande amostragem das experiências de saneamento no Brasil para definir aquelas que estavam alinhadas aos princípios da sustentabilidade. O Quadro 3 apresenta alguns exemplos deste alinhamento, que apontam para uma inovação na percepção estratégica dos gestores com relação aos padrões atuais. Estas decisões podem ter sido deliberadas em um Plano ou estar implícitas na visão de seus responsáveis, mas todas elas indicam uma buscar de melhor compreensão do ambiente externo e otimização das relações estabelecidas com este.

\section{Aspectos estratégicos do desenvolvimento sustentável}

Como se observa no Quadro 3, as ações que (proposital ou implicitamente) se encaminham para a sustentabilidade são guiadas por princípios, ou seja,

Quadro 2. Alguns problemas relacionados aos resíduos sólidos no Brasil.

\begin{tabular}{|c|c|}
\hline $\begin{array}{l}\text { Aspectos técnicos e } \\
\text { operacionais }\end{array}$ & $\begin{array}{l}\text { Adequação das áreas de disposição final: } 42 \% \text { das cidades } \\
\text { Existência de coleta seletiva: } 7 \% \text { das cidades } \\
\text { Custos da coleta seletiva: } \\
\text { - Santos: } \mathrm{R} \$ 587 / \mathrm{t} \\
\text { - Recife: } \mathrm{R} \$ 82 / \mathrm{t}\end{array}$ \\
\hline $\begin{array}{l}\text { Baixa disponibilidade de } \\
\text { recursos }\end{array}$ & $\begin{array}{l}\text { Gastos: } \leq 5 \% \text { do orçamento municipal } \\
\text { Gastos com pessoal específico: } \leq 5 \% \text { do orçamento municipal } \\
54 \% \text { dos municípios não cobram taxa de lixo } \\
\text { Terceirização }=1,24 \text { empresas/município }\end{array}$ \\
\hline $\begin{array}{l}\text { Padrões de produção e } \\
\text { consumo }\end{array}$ & $\begin{array}{l}\text { Geração de resíduos domiciliares: } 228.413 \text { t/dia (1,3 kg/hab.dia) } \\
\text { Aquisição de veículos: } 6 \% \text { do rendimento mensal } \\
\text { Demanda/oferta de computadores no País: } 96 \%\end{array}$ \\
\hline $\begin{array}{l}\text { Dinamismo do mercado } \\
\text { de recicláveis }\end{array}$ & $\begin{array}{l}\text { Reciclagem de Alumínio }=87 \% ; \text { Latas de aço }=49,5 \% ; \text { Papel }=43,9 \% \text { do total } \\
\text { Coleta seletiva formal: Alumínio }=1 \% ; \text { metais }=9 \% \text { do total } \\
\text { Cooperativas na coleta seletiva: } 43 \% \text { dos municípios com coleta seletiva } \\
\text { Catadores na área de disposição final: } 28 \% \text { dos municípios }\end{array}$ \\
\hline $\begin{array}{l}\text { Participação da população } \\
\text { na gestão }\end{array}$ & $\begin{array}{l}\text { Existência de conselhos ambientais: } 22,3 \% \text { dos municípios } \\
\text { Grau de identificação da população com as entidades: } 35 \%\end{array}$ \\
\hline
\end{tabular}

Fonte: Instituto Brasileiro de Geografia e Estatística (2000, 2002, 2003, 2004a, 2004b) e Compromisso Empresarial para a Reciclagem (2008). 
conceitos fundamentais que descrevem de forma ampla o comportamento ideal desejado. As definições de desenvolvimento sustentável são bastante polêmicas até hoje, mas pode-se afirmar que são constituídas fundamentalmente por dois momentos: um de percepção e monitoramento da realidade, e outro de direcionamento das ações. Para o primeiro, dada a amplitude do conceito em questão, costuma-se fazer a análise por dimensões e para o segundo, princípios genéricos ou específicos para as situações ou sistemas em foco.

A ONU (ORGANIZAÇÃO DAS NAÇÕES UNIDAS, 2001) atualmente sugere quatro grandes dimensões para a análise e definição de indicadores de sustentabilidade: social, ambiental, econômica e institucional. É conveniente descompô-las em temas em subtemas. Por exemplo, para a dimensão social, os temas: equidade, saúde, educação, etc; para a ambiental: atmosfera, águas, biodiversidade, etc. A dimensão ambiental está relacionada ao uso dos recursos naturais e à degradação do meio ambiente, bem como à sua preservação e conservação em benefício das gerações atuais e futuras. A social compreende os fatores para satisfação das necessidades humanas, a justiça social e a melhoria da qualidade de vida. Na esfera econômica, inclui-se não somente o desempenho macroeconômico e financeiro, como também os impactos quando do consumo de recursos naturais e energia primária, e a reprodução econômica sustentável a longo prazo

Quadro 3. Exemplos de ações positivas no saneamento ambiental brasileiro.

\begin{tabular}{|c|c|c|}
\hline Princípio & Objetivos & Decisões \\
\hline $\begin{array}{l}\text { Universa- } \\
\text { lidade }\end{array}$ & $\begin{array}{l}\text { Ampliar os serviços institucionais } \\
\text { Conceder isenções de taxa } \\
\text { Universalizar a coleta seletiva }\end{array}$ & $\begin{array}{l}\text { Modernização } \\
\text { Tarifas mais baixas } \\
\text { Condições para organização de catadores e suas } \\
\text { famílias }\end{array}$ \\
\hline Equidade & $\begin{array}{l}\text { Conceder isenções } \\
\text { Racionalizar despesas }\end{array}$ & $\begin{array}{l}\text { Conferência Municipal de Saúde } \\
\text { Realizar pregão }\end{array}$ \\
\hline $\begin{array}{l}\text { Integra- } \\
\text { lidade }\end{array}$ & $\begin{array}{l}\text { Racionalizar esforços } \\
\text { Aplicar o conceito de saneamento ambiental }\end{array}$ & $\begin{array}{l}\text { Criar Consórcio } \\
\text { Assumir a gestão de resíduos e educação } \\
\text { ambiental }\end{array}$ \\
\hline $\begin{array}{l}\text { Titularidade } \\
\text { municipal }\end{array}$ & Defender solidez da empresa pública & Impedir abertura de capital \\
\hline Gestão pública & $\begin{array}{l}\text { Gestão responsável e integrada } \\
\text { Desvincular contabilidade das contas da } \\
\text { prefeitura } \\
\text { Obter continuidade na administração dos } \\
\text { serviços }\end{array}$ & $\begin{array}{l}\text { Compartilhar decisões com população e } \\
\text { especialistas } \\
\text { Criar Autarquia } \\
\text { Usar técnicos do próprio quadro }\end{array}$ \\
\hline $\begin{array}{l}\text { Participação e } \\
\text { controle social }\end{array}$ & $\begin{array}{l}\text { Deliberação de políticas e ações da gestão } \\
\text { ambiental pela população } \\
\text { Melhorar canal de comunicação com } \\
\text { consumidor } \\
\text { Desenvolver e disseminar conhecimento } \\
\text { Impedir controle da empresa pública pela } \\
\text { iniciativa privada }\end{array}$ & $\begin{array}{l}\text { Conferência e Política Municipal de Saneamento } \\
\text { Ambiental } \\
\text { Parceria com universidades e ONGs } \\
\text { Criar Centro de Educação Ambiental } \\
\text { Controle social instituído por Lei } \\
\text { Criar Departamento de Comunicação }\end{array}$ \\
\hline $\begin{array}{l}\text { Interseto- } \\
\text { rialidade }\end{array}$ & $\begin{array}{l}\text { Democratizar saúde } \\
\text { Ressocializar detentos } \\
\text { Oferecer condições dignas e perspectivas } \\
\text { aos catadores } \\
\text { Adequar-se aos novos desafios como a } \\
\text { ocupação desordenada } \\
\text { Potencializar ações conjuntas }\end{array}$ & $\begin{array}{l}\text { Parceria para trabalho conjunto } \\
\text { Assistência Social, Saúde, Educação } \\
\text { Revisar Lei de Uso e Ocupação } \\
\text { Política de Saneamento integrada a outras } \\
\text { políticas públicas } \\
\text { Ações preventivas }\end{array}$ \\
\hline $\begin{array}{l}\text { Qualidade dos } \\
\text { serviços }\end{array}$ & $\begin{array}{l}\text { Minimizar perdas } \\
\text { Certificação ISO } 9001 \\
\text { Eficiência na tomada de decisões } \\
\text { Desenvolver os recursos humanos }\end{array}$ & $\begin{array}{l}\text { Combater desperdício } \\
\text { Medição dos serviços } \\
\text { Treinamento, Assistência e Segurança do Trabalho }\end{array}$ \\
\hline Acesso & $\begin{array}{l}\text { Fim do clientelismo na avaliação de } \\
\text { usuários inadimplentes }\end{array}$ & $\begin{array}{l}\text { Criar Fundo Social } \\
\text { Maior consumo subsidia menor consumo } \\
\text { Lei de responsabilização pelos resíduos }\end{array}$ \\
\hline
\end{tabular}

Fonte: Associação Nacional dos Serviçõs Municipais de Saneamento (2006). 
(eficiência da produção versus alteração nas estruturas de consumo). A importante dimensão institucional refere-se à orientação política, capacidade institucional e esforços despendidos para a implementação efetiva do desenvolvimento sustentável.

Quanto aos princípios para norteamento das ações, existe certo consenso sobre as diretrizes fundamentais, dentro das referências científicas e documentos relevantes como a Agenda 21, marco das discussões globais sobre desenvolvimento sustentável. Milanez (2002) compilou da bibliografia um conjunto de quinze princípios genéricos para a sustentabilidade: elementar (direito à vida saudável e produtiva), geração de renda, gestão cooperativa e participativa, equidade, eficiência econômica responsável, poluidor-pagador, paz, soberania e relações internacionais (ou entre esferas do Governo), respeito às condições locais, responsabilidade intergeracional, avaliação de impactos sociais e ambientais, precautório, preventivo, uso racional dos recursos naturais e compensação dos impactos e danos.

\section{Estruturação da estratégia utilizando o Balanced Scorecard}

Mintzberg (1987) explica que a estratégia pode ser definida por cinco formas ("5 Pês"), mais ou menos determinantes no comportamento geral das organizações:

- Plano: um conjunto de diretrizes, com a deliberação de um curso de ação específico;

- Pretexto: uma manobra específica para superar os concorrentes;

- Padrão: uma consistência que pode ser inferida dos comportamentos dentro da empresa;

- Posição: situação da empresa em seu meio (ambiente interno versus externo); e

- Perspectiva: visão ampla que representa a cultura e a "personalidade" organizacionais (MINTZBERG, 1987).

Estes aspectos configuram-se em um modelo de decisões representado por objetivos estratégicos, aos quais são alinhadas as políticas e sequências de ação - programas - da organização (ANDREWS, 1980; QUINN, 1980). Tal é a hierarquia normalmente apresentada pelos mapas cognitivos. O mapeamento cognitivo é uma técnica para estruturação de problemas complexos, que faz uma representação visual mais próxima da realidade, ao identificar os conceitos essenciais ('constructos', no mapa), e as relações causais entre eles ('setas').

O processo de mapeamento consiste em, a partir de depoimentos originados por entrevistas ou material teórico, separar as frases em conceitos principais, conceitos estes que devem prioritariamente estar direcionados à ação (com verbos ou substantivos que indiquem ação). Os objetivos (conquistas) são normalmente posicionados no topo do mapa, com as direções estratégicas baixo, e as opções potenciais (normalmente atividades) na base. Ou seja, de forma que as relações causais apresentem um fluxo de baixo para cima. As setas podem ser direcionadas em um ou nos dois sentidos, e podem representar relações de causalidade direta ou inversa (em que 'mais' de uma causa implica em 'menos' de uma consequência). Os benefícios em utilizar esta técnica são: estruturar, organizar e analisar as ideias sobre um problema; identificar objetivos, pontos críticos, loops e conflitos; esclarecimento e referência para entrevistas posteriores, e busca do consenso (ACKERMAN; EDEN; CROPPER, 1992).

O Balanced Scorecard (BSC) também atua na sistematização desta hierarquia estratégica, comunicando-a visualmente por meio dos scorecards ('quadros de indicadores') e o mapa estratégico, uma forma de mapa cognitivo responsável pelo 'balanceamento' dos objetivos segundo perspectivas (grupos de temas com a mesma natureza). Os scorecards são quadros, também categorizados por perspectivas, que representam, para cada objetivo estratégico, as respectivas metas, indicadores de desempenho e ações. Eles permitem esclarecer e controlar os aspectos relativos a cada objetivo estratégico definido.

O mapa estratégico é um diagrama que conecta os objetivos em uma sequência lógica e verticalmente causal, classificados por perspectivas, as quais normalmente apresentam a seguinte hierarquia causal:

Aprendizado e Crescimento $\rightarrow$ Processos Internos Clientes $\rightarrow$ Finanças (KAPLAN; NORTON, 1996).

Embora esta configuração seja bastante comum e eficiente na representação das estratégias de empresas privadas, sempre há a possibilidade de redefinição das perspectivas, de acordo com a natureza dos objetivos estratégicos. Esta adaptação é particularmente interessante nas estratégias para o setor público, no qual a lucratividade não é o objetivo principal. Normalmente, o que ocorre é a redefinição da perspectiva 'Clientes' como 'População' ou 'Sociedade', e seu posicionamento no topo do mapa, acima ou ao lado da perspectiva financeira (KAPLAN; NORTON, 2004). Um exemplo de aplicação do BSC no setor público brasileiro é a Prefeitura de Porto Alegre (RS).

$\mathrm{O}$ processo de concepção do $\mathrm{BSC}$ obedece à seguinte sequência:

Visão (para o futuro) $\rightarrow$ Perspectivas $\rightarrow$ Objetivos $\rightarrow$ Pontos Críticos $\rightarrow$ Indicadores $\rightarrow$ Ações (OLVE; ROY; WETTER, 1999)

Inicialmente é definida qual a Missão da organização ('por que existimos?'), seguida da Visão ('onde queremos chegar no futuro?'). Esta visão deve nortear a definição das perspectivas estratégicas, e dos objetivos, processo este que pode ser auxiliado pela utilização 
do mapeamento cognitivo. Uma vez definidos os objetivos, são identificados os pontos críticos que serão mensurados pelos indicadores, e que irão nortear as ações para conquistar os objetivos. Desta forma, a visão estratégica pode ser eficazmente comunicada para toda a organização, e são construídos scorecards individuais para os principais departamentos, ou seja, objetivos, metas e ações específicas que permitirão o alinhamento de cada departamento aos objetivos organizacionais.

\section{Estudo de caso: concepção de um Balanced Scorecard em um consórcio intermunicipal para gestão de resíduos sólidos entre os municípios de Araraquara e \\ São Carlos - SP}

Para este trabalho, foram realizadas entrevistas abertas e semiestruturadas, feitas individualmente com pessoas que ocupam cargo de gerência nos sistemas de resíduos sólidos dos dois municípios em estudo. Considerou-se, como membros da alta direção do consórcio, o Superintendente do DAAE-Araraquara, Autarquia responsável pelos serviços de saneamento ambiental neste município, e o Diretor de Política Ambiental de São Carlos, vinculado à Secretaria Municipal de Desenvolvimento Sustentável, Ciência e Tecnologia, nos anos de 2006 e 2007.

As entrevistas com a alta direção respeitaram dois momentos:

- Entrevistas temáticas: foram feitas perguntas buscando extrair a visão dos gestores sobre temas associados às dimensões da sustentabilidade. Ex.: Quais os fatores que atualmente influenciam a implantação de políticas de longo prazo na gestão de resíduos do município? (Tema: Continuidade Administrativa, Dimensão Institucional). Quais devem ser as condições ideais para o tratamento dos resíduos sólidos locais e regionais? (Tema: Conservação do Meio Ambiente, Dimensão Ambiental);

- Entrevistas baseadas nos princípios da sustentabilidade: os princípios para o desenvolvimento sustentável compilados por Milanez (2002) e mencionados acima foram apresentados aos altos gestores, os quais foram inquiridos a interpretar estes conceitos sob a realidade local e especificamente a gestão de resíduos sólidos, de forma a adequá-los e reescrevê-los de forma mais específica; e

- Entrevistas para construção do Balanced Scorecard do Consórcio: de posse dos objetivos estratégicos obtidos, foram derivados os indicadores e possíveis ações estratégicas, além de construído o mapa estratégico.
Também foram feitas entrevistas com ocupantes de cargos de chefia de departamentos nestes sistemas em estudo, tendo sido apresentados os objetivos gerais do Consórcio, para que posteriormente fossem interpretados sob as responsabilidades daquelas funções específicas, derivando objetivos restritos, bem como indicadores e possíveis ações.

Com relação às entrevistas temáticas aplicadas à alta gerência, as respostas foram gravadas, transcritas, e então foram identificados os conceitos e termos nucleares que permearam os discursos. Neste processo, utilizou-se o mapeamento cognitivo para verificação da hierarquia entre os fatores mencionados e para verificar aqueles que podem ser objetivos estratégicos e aqueles que somente se referem a ações, instrumentos ou alternativas. O mapa cognitivo final pode ser visto na Figura 2, onde os potenciais objetivos estão destacados em amarelo. Para melhor compreensão do processo de mapeamento, considere-se o exemplo abaixo, referente a uma citação do Gestor 2 (Figura 1):

[...] a diretriz tem que ser seguida, o arranjo institucional também, e daí comunicar todos os papéis. Qual o papel do Governo, o do cidadão, o da empresa, o do comércio, todo mundo tem que ter um papel definido, cada um com seu papel, você tem que mexer no arcabouço legal, normas, leis... [...] Pra população, por exemplo, tem que definir meta. Meta legal quer dizer: leis, normas que sejam exequíveis. Não adianta fazer uma lei sem pé nem cabeça que ninguém vai cumprir. Tem que fazer coisa que dê pra fazer, que seja exequível, que se tenha instrumento e meio pra fazer a lei ser cumprida. Tratar com eficiência, essas coisas. Não adianta você querer copiar uma lei que deu certo na França e querer aplicar aqui, que não vai dar certo.

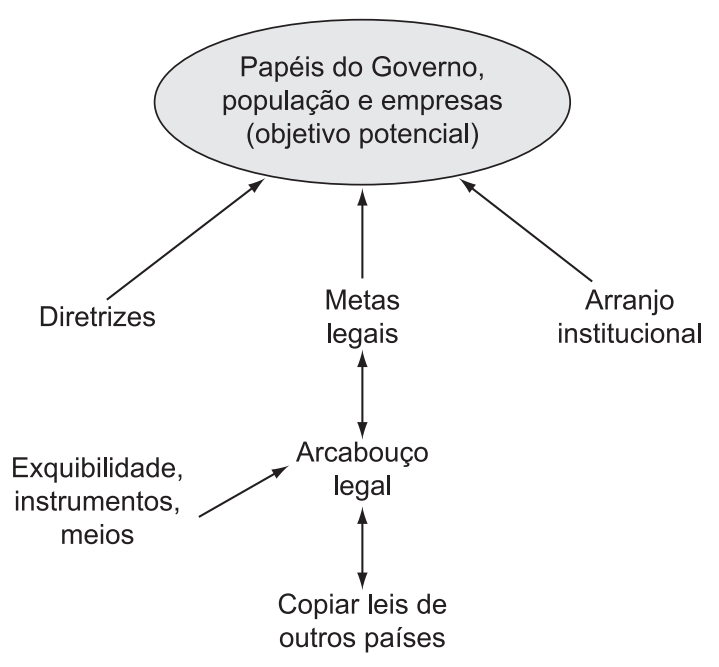

Figura 1. Exemplo de hierarquia de conceitos segundo a visão dos gestores. Fonte: Souza (2007). 


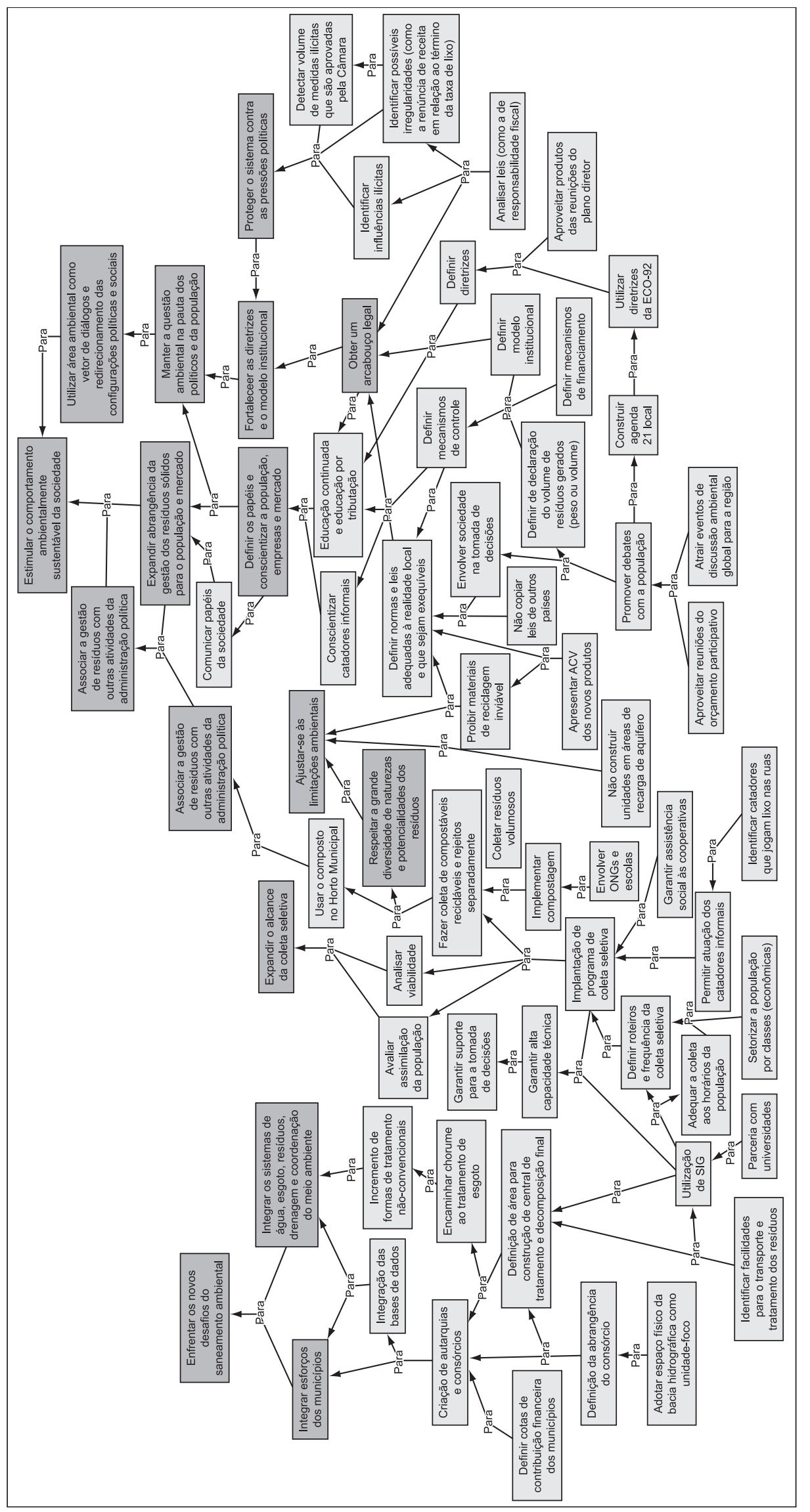

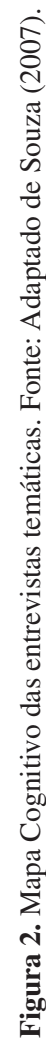


A Figura 2 traduz os discursos dos dois gestores entrevistados, com respeito às questões relacionadas à adequação de seus sistemas segundo os temas de sustentabilidade definidos. Percebe-se claramente que a hierarquia obtida elucida que constructos são relativos a opções potenciais, ou ações - aqueles dos quais somente saem setas, e quais são aqueles que mais se assemelham a pontos críticos ou objetivos estratégicos potenciais - aqueles que concentram grande quantidade de setas, e aqueles que somente recebem setas. Além disto, foram observadas as características dos conceitos, ou seja, se correspondem a ações diretas, ou se se assemelham a objetivos, ou seja, pontos a serem conquistados.

Quanto às entrevistas baseadas nos princípios da sustentabilidade, pela própria natureza destes conceitos - o direcionamento das ações - , apresentaram fatores mais próximos daquilo que caracteriza um objetivo estratégico potencial, como os identificados no exemplo a seguir:

- Princípio da gestão cooperativa e participativa:

- reconhecer e respeitar as diversidades da sociedade, oferecendo uma estrutura de apoio (Gestor 2);

- integrar os níveis de Governo para garantir a continuidade de políticas (Gestor 2); e

- integrar horizontalmente as partes para a gestão ambiental adequada, pela conscientização, união das consciências e respeito ao meio ambiente e sua diversidade (Gestor 1 - SOUZA, 2007).

Os conceitos principais ou potenciais objetivos estratégicos obtidos por estas duas formas de entrevistas foram reunidos e, então, agrupados de acordo com a semelhança de suas naturezas (clusters de conceitos). Dos onze grupos que surgiram, foi feita uma síntese que resultou nos onze objetivos estratégicos do Consórcio. Por exemplo, para o Objetivo O5:

- Grupo de objetivos potenciais $\mathrm{N}^{\circ} .5$ :

- integrar esforços dos municípios para enfrentar os desafios do saneamento ambiental (Gestor 1, Gestor 2, Entrevistas Temáticas);

- integrar os sistemas de saneamento ambiental (Gestor 1, Gestor 2, Entrevistas Temáticas);

- integrar os níveis de governo para garantir continuidade de políticas (Gestor 2 Princípios - Gestão Cooperativa e Participativa);

- associar G.R.S.U. a outras atividades da administração pública (Gestor 1 Entrevistas Temáticas);
- expandir a gestão de resíduos sólidos para a população e o mercado (Gestor 2 Entrevistas Temáticas);

- associar a gestão de resíduos às atividades diversas da sociedade (Gestor 1 - Entrevistas Temáticas);

- integrar horizontalmente as partes para a gestão ambiental adequada, pela conscientização, união das consciências e respeito ao meio ambiente e sua diversidade (Gestor 1 - Princípios - Gestão Cooperativa e Participativa); e

- manter a questão ambiental na pauta dos políticos e da população (Gestor 1 Entrevistas Temáticas).

Objetivo O5: Integrar e associar a gestão de resíduos com os outros sistemas de saneamento, setores da administração pública, outros municípios, níveis de governo e atividades da sociedade civil, promovendo a união de esforços e de consciências (Integração dos Esforços).

Os onze objetivos finais obtidos, que estão apresentados no Quadro 4, foram submetidos a uma avaliação pelos altos gestores, verificando o seu grau de atendimento a critérios obtidos na literatura sobre as características ideais dos objetivos estratégicos corporativos - ter estabilidade; dar uma orientação clara para o futuro; justificar o comprometimento; ter alcance corporativo; referir-se a pontos críticos atuais; e traduzir a essência da vitória (HAMEL; PRAHALAD, 1989; KAPLAN; NORTON, 1997). Foram atribuídas pelos gestores notas de 0 a 10 para esta verificação de objetivo versus critério. Notou-se uma boa eficiência no resultado final deste processo, conforme se observa na Tabela 1 (as notas dadas pelos gestores estão entre parênteses, e as médias em negrito).

Nota-se que os objetivos com maior média são: O2, O5, O8, O11. Isto indica uma priorização, por parte dos gestores, para os aspectos relacionados à mobilização da sociedade e o envolvimento direto com a gestão. Portanto, isto poderia caracterizar um perfil da gestão deste Consórcio. O objetivo com a menor média $(7,33)$ foi o $\mathrm{O} 7$ - Melhor Capacitação Técnica, o qual foi considerado ainda assim essencial pelos gestores e assim mantido na estratégia final.

Também foi verificada a maior influência dos princípios em relação aos temas na consecução dos objetivos estratégicos. Esta medição se deu pelo número de conceitos-chave (objetivos potenciais) contidos nos grupos que foram compilados, em relação a qual momento de entrevistas - temáticas ou sobre os princípios - surgiram os conceitos. Esta relação está apresentada na Figura 3, em termos de porcentagem de conceitos surgidos por cada tipo de 
entrevista (temas ou princípios), em relação ao total de objetivos potenciais de cada grupo (cluster). $\mathrm{O}$ resultado somente comprova que as discussões sobre os princípios os posiciona no topo da hierarquia estratégica, como elementos da Visão para o futuro, derivando diretamente deles os objetivos estratégicos, ao passo que os temas assemelham-se às perspectivas do BSC, que são detalhadas em termos de objetivos, pontos críticos e ações (como no mapa da Figura 2).

Para a construção do mapa estratégico, foram apresentados aos gestores os objetivos finais, e foi solicitado que conectassem estes conceitos por meio de setas:

- Setas em um único sentido: relação causa-efeito direta de um objetivo em relação ao outro; e

- Setas em duplo sentido: relação de causalidade mútua entre dois objetivos.

As setas também variavam em função da forma de causalidade entre os objetivos: setas com linha cheia, para relações em que mais de um implica em mais do outro, e setas com linha tracejada, em que mais de um provoca menos do outro, ou vice-versa. Embora um tanto confuso, o mapa cognitivo auxiliar da Figura 4 permitiu uma melhor compreensão sobre como os gestores visualizavam as relações causais existentes entre os objetivos; também permitiu identificar suas características hierárquicas, ou seja, se potencialmente são objetivos de topo ('entram' mais setas do que 'saem'), ou de base (mais setas 'saindo').

Ao final, as conexões foram quantificadas (Tabela 2) segundo a entrada ou saída em cada constructo de objetivo estratégico. Analisando os dados da Tabela 2, foi possível compreender a posição hierárquica aplicável a cada objetivo, embora este processo não tenha prescindido de certa subjetividade pelo pesquisador, o que, no entanto, é comum nos processos de mapeamento. Notou-se que a distribuição dos objetivos caracterizava as perspectivas desta estratégia, e assim foi definido o mapa estratégico final para o Consórcio (Figura 5).

Observou-se que os fatores mais fundamentais da estratégia (aqueles dos quais saem mais setas do que entram, como a Sensibilização e Conscientização), estavam associados à perspectiva inicial do BSC de Aprendizado e Crescimento, ao passo que os objetivos finais (recebem mais que originam setas, como o Fortalecimento Institucional), se relacionavam à Dimensão Institucional dos conceitos de sustentabilidade. Os aspectos intermediários puderam ser classificados dentro das perspectivas de Processos Internos (Operacionais) e da Sociedade. Estabeleceu-se, assim, uma hierarquia estratégica que respeita o modelo original do Balanced

Tabela 1. Avaliação dos objetivos em função dos critérios estratégicos.

\begin{tabular}{|c|c|c|c|c|c|c|c|}
\hline & & $\begin{array}{l}\text { Essência } \\
\text { da vitória }\end{array}$ & $\begin{array}{l}\text { Pontos } \\
\text { críticos } \\
\text { atuais }\end{array}$ & $\begin{array}{c}\text { Alcance } \\
\text { corporativo }\end{array}$ & $\begin{array}{c}\text { Justificar } \\
\text { comprometimento }\end{array}$ & $\begin{array}{c}\text { Orientação } \\
\text { clara para } \\
\text { o futuro }\end{array}$ & $\begin{array}{c}\text { Estabilidade } \\
\text { e } \\
\text { consistência }\end{array}$ \\
\hline $\mathrm{O} 1$ & $\begin{array}{l}\text { Otimizar ciclo de } \\
\text { vida dos resíduos }\end{array}$ & $\begin{array}{c}(10,10) \\
10\end{array}$ & $\begin{array}{c}(7,8) \\
7,5\end{array}$ & $\begin{array}{c}(8,8) \\
8\end{array}$ & $\begin{array}{c}(7,8) \\
7,5\end{array}$ & $\begin{array}{c}(10,10) \\
10\end{array}$ & $\begin{array}{c}(10,10) \\
10\end{array}$ \\
\hline $\mathrm{O} 2$ & $\begin{array}{l}\text { Sensibilização e } \\
\text { conscientização }\end{array}$ & $\begin{array}{c}(10,10) \\
10\end{array}$ & $\begin{array}{c}(10,10) \\
10\end{array}$ & $\begin{array}{c}(10,10) \\
10\end{array}$ & $\begin{array}{c}(10,10) \\
10\end{array}$ & $\begin{array}{c}(5,10) \\
7,5\end{array}$ & $\begin{array}{c}(7,10) \\
8,5\end{array}$ \\
\hline $\mathrm{O} 3$ & $\begin{array}{l}\text { Respeitar } \\
\text { diversidades }\end{array}$ & $\begin{array}{c}(7,10) \\
8,5\end{array}$ & $\begin{array}{c}(10,10) \\
10\end{array}$ & $\begin{array}{c}(5,10) \\
7,5\end{array}$ & $\begin{array}{c}(8,10) \\
9\end{array}$ & $\begin{array}{c}(8,10) \\
9\end{array}$ & $\begin{array}{c}(5,10) \\
7,5\end{array}$ \\
\hline $\mathrm{O} 4$ & $\begin{array}{l}\text { Eficiência da coleta } \\
\text { seletiva }\end{array}$ & $\begin{array}{c}(7,10) \\
8,5\end{array}$ & $\begin{array}{c}(7,10) \\
8,5\end{array}$ & $\begin{array}{c}(10,10) \\
10\end{array}$ & $\begin{array}{c}(7,10) \\
8,5\end{array}$ & $\begin{array}{c}(7,10) \\
8,5\end{array}$ & $\begin{array}{c}(10,10) \\
10\end{array}$ \\
\hline O5 & $\begin{array}{l}\text { Integração da } \\
\text { gestão }\end{array}$ & $\begin{array}{c}(10,10) \\
10\end{array}$ & $\begin{array}{c}(8,10) \\
9\end{array}$ & $\begin{array}{c}(10,10) \\
10\end{array}$ & $\begin{array}{c}(10,10) \\
10\end{array}$ & $\begin{array}{c}(5,10) \\
7,5\end{array}$ & $\begin{array}{c}(10,10) \\
10\end{array}$ \\
\hline O6 & $\begin{array}{l}\text { Fortalecimento } \\
\text { institucional }\end{array}$ & $\begin{array}{c}(7,10) \\
8,5\end{array}$ & $\begin{array}{c}(10,10) \\
10\end{array}$ & $\begin{array}{c}(7,10) \\
8,5\end{array}$ & $\begin{array}{c}(7,10) \\
8,5\end{array}$ & $\begin{array}{c}(5,10) \\
7,5\end{array}$ & $\begin{array}{c}(8,10) \\
9\end{array}$ \\
\hline O7 & $\begin{array}{l}\text { Melhor capacitação } \\
\text { técnica }\end{array}$ & $\begin{array}{c}(8,8) \\
8\end{array}$ & $\begin{array}{c}(7,8) \\
7,5\end{array}$ & $\begin{array}{c}(9,8) \\
8,5\end{array}$ & $\begin{array}{c}(8,8) \\
8\end{array}$ & $\begin{array}{c}(6,5) \\
5,5\end{array}$ & $\begin{array}{c}(8,5) \\
6,5\end{array}$ \\
\hline O8 & Internalizar custos & $\begin{array}{c}(8,10) \\
9\end{array}$ & $\begin{array}{c}(10,10) \\
10\end{array}$ & $\begin{array}{c}(5,10) \\
7,5\end{array}$ & $\begin{array}{c}(10,10) \\
10\end{array}$ & $\begin{array}{c}(10,10) \\
10\end{array}$ & $\begin{array}{c}(10,10) \\
10\end{array}$ \\
\hline O9 & $\begin{array}{l}\text { Precaução nos } \\
\text { projetos }\end{array}$ & $\begin{array}{c}(8,10) \\
9\end{array}$ & $\begin{array}{c}(10,10) \\
10\end{array}$ & $\begin{array}{l}(7,10) \\
8,5\end{array}$ & $\begin{array}{c}(10,10) \\
10\end{array}$ & $\begin{array}{c}(10,10) \\
10\end{array}$ & $\begin{array}{c}(10,10) \\
10\end{array}$ \\
\hline $\mathrm{O} 10$ & Compensar danos & $\begin{array}{c}(8,10) \\
9\end{array}$ & $\begin{array}{c}(6,10) \\
8\end{array}$ & $\begin{array}{c}(8,10) \\
9\end{array}$ & $\begin{array}{c}(8,10) \\
9\end{array}$ & $\begin{array}{c}(5,10) \\
7,5\end{array}$ & $\begin{array}{c}(8,10) \\
9\end{array}$ \\
\hline $\mathrm{O} 11$ & $\begin{array}{l}\text { Gestão das } \\
\text { informações }\end{array}$ & $\begin{array}{c}(9,10) \\
9,5\end{array}$ & $\begin{array}{c}(8,10) \\
9\end{array}$ & $\begin{array}{c}(10,10) \\
10\end{array}$ & $\begin{array}{c}(10,10) \\
10\end{array}$ & $\begin{array}{c}(10,10) \\
10\end{array}$ & $\begin{array}{c}(10,10) \\
10\end{array}$ \\
\hline
\end{tabular}

Fonte: Souza, 2007. 
Quadro 4. Objetivos estratégicos finais definidos para o Consórcio.

\begin{tabular}{|c|c|}
\hline Objetivos & Descrição \\
\hline $\begin{array}{l}\text { O1: otimização do ciclo de vida } \\
\text { dos resíduos }\end{array}$ & $\begin{array}{l}\text { Reduzir, controlar e retornar ao máximo os resíduos à cadeia produtiva, } \\
\text { respeitando as limitações da natureza e a diversidade dos materiais, pela ACV } \\
\text { inclusive dentro da gestão de resíduos, atenção aos novos produtos e recursos } \\
\text { naturais não renováveis e a promoção de políticas de minimização de rejeitos. }\end{array}$ \\
\hline $\begin{array}{l}\text { O2: sensibilização e } \\
\text { conscientização }\end{array}$ & $\begin{array}{l}\text { Promover a conscientização da população, empresas, cooperativas, e catadores } \\
\text { informais para assumirem um papel ambientalmente correto. }\end{array}$ \\
\hline O3: respeito às diversidades & $\begin{array}{l}\text { Garantir que a gestão e as políticas respeitem as diversidades existentes na } \\
\text { sociedade, favorecendo a boa qualidade de vida, inclusive dos catadores. }\end{array}$ \\
\hline O4: eficiência da coleta seletiva & $\begin{array}{l}\text { Fazer uma coleta seletiva eficiente, expansiva e adequada aos horários da } \\
\text { população. }\end{array}$ \\
\hline O5: integração dos esforços & $\begin{array}{l}\text { Integrar e associar a gestão de resíduos com outros sistemas de saneamento, } \\
\text { setores da administração pública, outros municípios, níveis de governo e } \\
\text { atividades da sociedade civil, promovendo a união de esforços e consciências. }\end{array}$ \\
\hline O6: fortalecimento institucional & $\begin{array}{l}\text { Fortalecer a instituição e suas diretrizes contra as pressões externas, sejam } \\
\text { políticas ou nas relações de interdependência e estratégicas, por meio da } \\
\text { soberania e de um consistente arcabouço legal. }\end{array}$ \\
\hline O7: melhor capacitação técnica & $\begin{array}{l}\text { Buscar a alta capacitação técnica para elaboração e análise de projetos e } \\
\text { suporte à tomada de decisões no planejamento, adequando-se à realidade do } \\
\text { sistema e evitando a imitação de outras experiências. }\end{array}$ \\
\hline O8: internalização dos custos & $\begin{array}{l}\text { Considerar indissociáveis a eficiência econômica e ambiental, ao internalizar } \\
\text { os custos ambientais e valorar os recursos naturais e os impactos na medida do } \\
\text { possível. }\end{array}$ \\
\hline O9: precaução nos projetos & $\begin{array}{l}\text { Prever, na elaboração dos projetos, os impactos e sua reversibilidade e os } \\
\text { custos da futura remediação e medidas mitigadoras. A escolha da área de } \\
\text { disposição final deve buscar as áreas com maior impermeabilidade natural, } \\
\text { embora haja tecnologia para tal proteção, mantendo os padrões de qualidade } \\
\text { dos recursos naturais inclusive para os municípios vizinhos. }\end{array}$ \\
\hline O10: compensação dos impactos & $\begin{array}{l}\text { Fornecer compensação social e ambiental às vítimas e áreas de impacto de } \\
\text { projetos, utilizando a moral e a idoneidade de forma a superar o dano causado. }\end{array}$ \\
\hline O11: gestão das informações & $\begin{array}{l}\text { Promover a boa gestão das informações para facilitação das avaliações e } \\
\text { comunicação dos riscos e instruções à população, valendo-se para tal da } \\
\text { potencialidade das universidades. }\end{array}$ \\
\hline
\end{tabular}

Fonte: Souza (2007).

Tabela 2. Número e tipos de conexões dos objetivos estratégicos.

O1 - Otimização do ciclo de vida

$\mathrm{O} 2$ - Sensibilização e conscientização

$\mathrm{O} 3$ - Respeito às diversidades da sociedade

O4 - Eficiência da coleta seletiva

O5 - Integração dos esforços

O6 - Fortalecimento institucional

O7 - Melhor capacitação técnica

O8 - Internalização dos custos

O9 - Precaução nos projetos

O10 - Compensação dos impactos

O11 - Gestão das informações
$4($ Entrada $=3 ;$ Saída $=3 ;$ Duplo sentido $=2)$

$7($ Entrada $=4 ;$ Saída $=7 ;$ Duplo sentido $=4)$

$5($ Entrada $=2 ;$ Saída $=5 ;$ Duplo sentido $=2)$

$5($ Entrada $=3 ;$ Saída $=3 ;$ Duplo sentido $=1)$

$5($ Entrada $=5 ;$ Saída $=5 ;$ Duplo sentido $=5)$

$6($ Entrada $=6 ;$ Saída $=3 ;$ Duplo sentido $=3)$

$7($ Entrada $=4 ;$ Saída $=7 ;$ Duplo sentido $=4)$

$5($ Entrada $=3 ;$ Saída $=4 ;$ Duplo sentido $=2)$

$4($ Entrada $=3 ;$ Saída $=1 ;$ Duplo sentido $=0)$

$6($ Entrada $=6 ;$ Saída $=0 ;$ Duplo sentido $=0)$

$6($ Entrada $=5 ;$ Saída $=6 ;$ Duplo sentido $=5)$

Fonte: Souza (2007). 
Scorecard, e introduz com relevância os aspectos do desenvolvimento sustentável, de forma integrada.

Por meio do mapa estratégico final, verifica-se que a estratégia inicia-se por um processo de capacitação interna, gestão das informações, e mobilização da população. Isto é muito coerente, especialmente pela semelhança com a perspectiva de base tradicional do BSC - Aprendizado e Crescimento, as primeiras conquistas a serem feitas antes de promoverem-se as transformações no processo operacional. Em seguida, a dimensão operacional, concentrada numa coleta seletiva mais eficiente, na elaboração de projetos bem

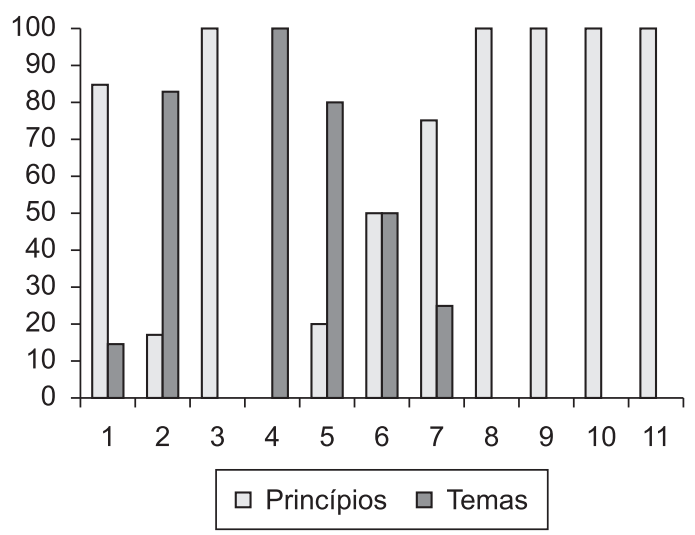

Figura 3. Influência dos princípios e dos temas nos objetivos finais. Fonte: Souza, 2007. fundamentada tecnicamente, e a otimização do ciclo de vida dos resíduos, o que implica no monitoramento do ciclo e busca da minimização de rejeitos. Todos estes aspectos permitem, por um lado, a integração dos esforços entre governo e sociedade e, por outro, o respeito às diversidades, este principalmente permitido pela precaução nos projetos. Havendo tais conquistas na perspectiva da Sociedade, é possível buscar o maior fortalecimento do Consórcio e a internalização dos custos, pois é adquirida confiabilidade no sistema e, com as conquistas anteriores, é possível distribuir as responsabilidades financeiras também pela sociedade. Todos estes aspectos permitem ao sistema oferecer compensação aos impactos causados, o que demanda recursos financeiros e envolvimento dos diversos atores do governo e sociedade. Este objetivo de topo, no entanto, refere-se a algo indesejável (os impactos) e que tende a ser minimizado de acordo com a evolução dos objetivos anteriores (observando a predominância de setas tracejadas que o alcançam).

Esta estratégia busca, inicialmente, construir uma maior solidez para o Consórcio (dimensão institucional no topo). Em outras palavras, por meio da busca pela sustentabilidade, visa-se conquistar a autossustentação do Consórcio, em seu primeiro momento. Possivelmente, uma estratégia posterior poderia dar maior ênfase, por exemplo, aos aspectos da sociedade e meio ambiente, uma vez que o Consórcio já se encontraria fortalecido institucional e financeiramente. Ainda assim, verifica-se que a

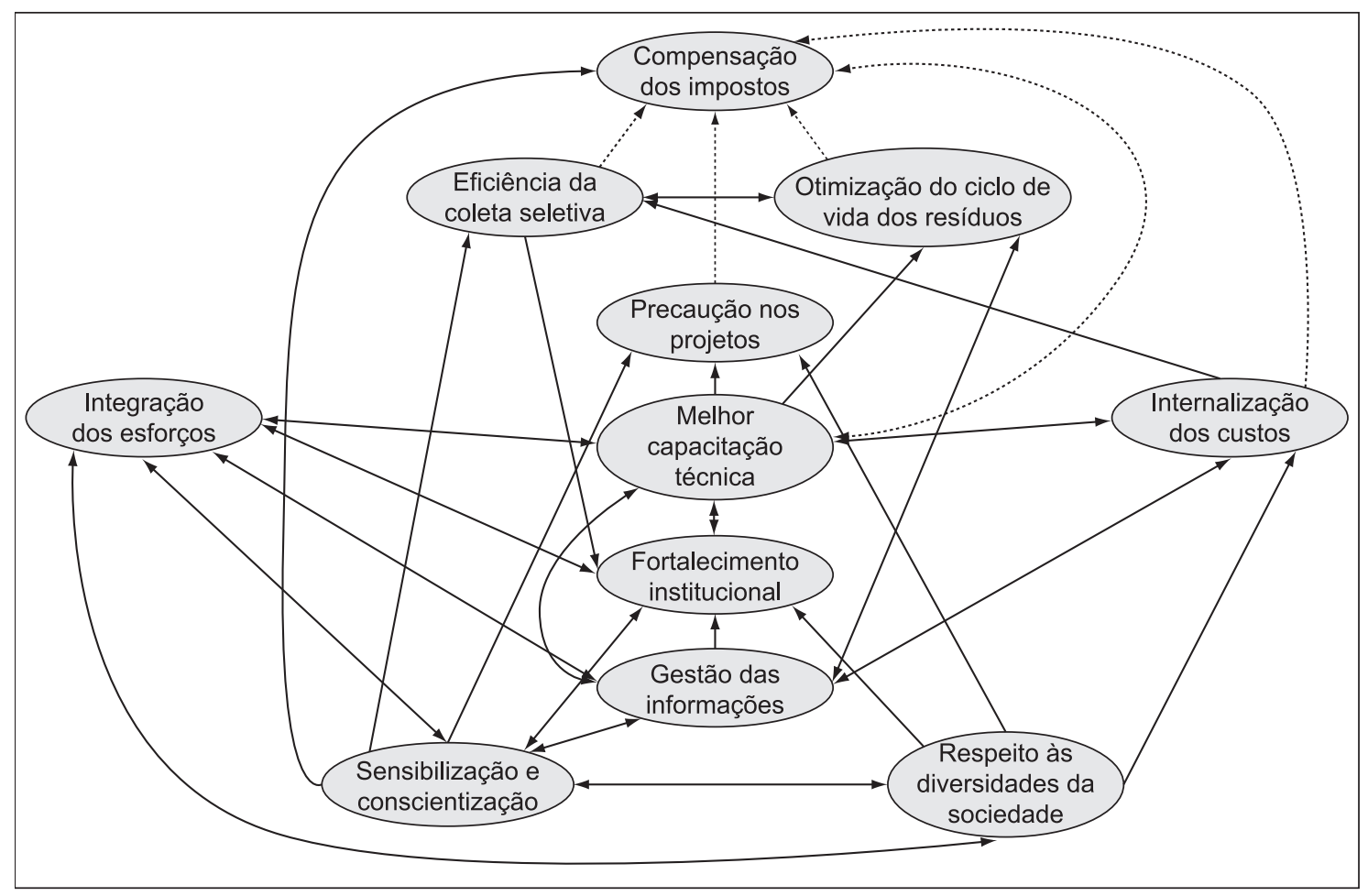

Figura 4. Mapa cognitivo inicial para os objetivos. Fonte: Souza (2007). 
Quadro 5. Scorecard da perspectiva processos operacionais.

\begin{tabular}{|lll|}
\hline \multicolumn{1}{|c}{ Objetivo } & \multicolumn{1}{c|}{ Indicadores } & \multicolumn{1}{c|}{ Iniciativas } \\
\hline $\begin{array}{l}\text { O4 - Eficiência da } \\
\text { coleta seletiva }\end{array}$ & $\begin{array}{l}\text { - Quantidade de resíduos/mês coletada } \\
\text { pela coleta seletiva/população/área (ou } \\
\text { bairros) }\end{array}$ & $\begin{array}{l}\text { - Fazer educação ambiental } \\
\text { - Tornar obrigatória a separação dos } \\
\text { resíduos }\end{array}$ \\
$\begin{array}{l}\text { O9 - Precaução nos } \\
\text { projetos }\end{array}$ & $-\mathrm{N}^{\text {o }}$. de impactos produzidos/mês, ano & $\begin{array}{l}\text { - Elaborar projetos com alta capacidade } \\
\text { técnica, transparência e publicidade para o }\end{array}$ \\
O1 - Otimização & afetados pelos impactos & conhecimento e apreciação da sociedade \\
do ciclo de vida dos & que chegam ao aterro & - Taxa de crescimento da população/taxa \\
produtos & de crescimento da produção de resíduos & $\begin{array}{l}\text { compostáveis maximizados } \\
\text { - Gerir resíduos sólidos perigosos, resíduos } \\
\text { tecnológicos, de serviços de saúde e da } \\
\text { construção civil }\end{array}$ \\
\hline
\end{tabular}

Fonte: Souza (2007).

Quadro 6. Scorecard do departamento jurídico.

\begin{tabular}{|c|c|}
\hline Objetivos & Iniciativas \\
\hline $\begin{array}{l}\text { Monitorar leis reguladoras buscando } \\
\text { reduzir os impactos dos novos produtos }\end{array}$ & $\begin{array}{l}\text { Manter a atenção sobre as condições de inconstitucionalidade das leis } \\
\text { aprovadas na Câmara permitindo a inserção de novos produtos }\end{array}$ \\
\hline $\begin{array}{l}\text { Buscar a inserção dos catadores num } \\
\text { especial sistema previdenciário }\end{array}$ & - Criar Fundo de Aposentadoria Social no Consórcio \\
\hline Proteção legal da instituição & $\begin{array}{l}\text { - Estatuto do Consórcio de acordo com a Constituição } \\
\text { - Estimular a formação de equipes multidisciplinares no planejamento }\end{array}$ \\
\hline $\begin{array}{l}\text { Estimular a aceitação favorável dos } \\
\text { projetos pela população }\end{array}$ & $\begin{array}{l}\text { Concessão de isenções de impostos e taxas em função da desvalorização } \\
\text { do imóvel causada pelos projetos }\end{array}$ \\
\hline
\end{tabular}

Fonte: Souza (2007).

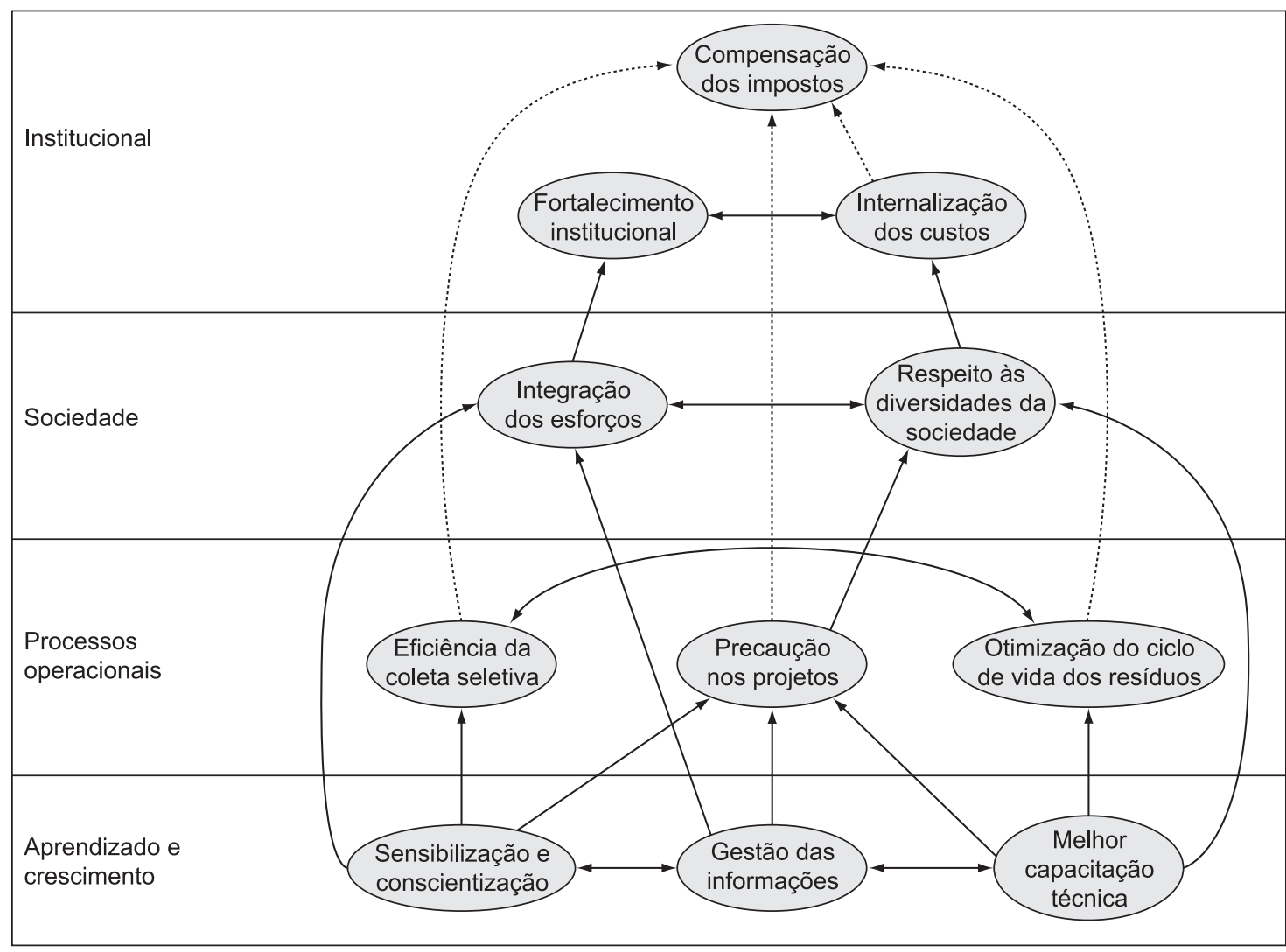

Figura 5. Mapa estratégico do Consórcio proposto para estudo. Fonte: Souza (2007). 
sustentabilidade pode ser garantida pelos processos operacionais, que visam o menor impacto ambiental e social, e com maior eficiência dos recursos, e os objetivos da sociedade, que garantem o atendimento aos critérios de qualidade de vida, nos pontos em que se implica a gestão de resíduos. Fazendo um paralelo com os problemas apresentados no Quadro 2, observa-se que todos eles são combatidos pela estratégia, em todas as perspectivas, mas especialmente nos processos operacionais. Também há grande semelhança com os princípios e objetivos apresentados no Quadro 3, relativos às experiências de maior êxito no saneamento ambiental brasileiro.

O Quadro 5 apresenta o scorecard obtido junto à alta gerência para a Perspectiva dos Processos Operacionais. Este scorecard elucida como os gestores pretendem monitorar o desempenho dos objetivos O1, O4 e O9, e que ações são consideradas fundamentais para sua consecução. O Quadro 6 exemplifica um scorecard construído para o Departamento Jurídico, construído com o auxílio do Chefe da Procuradoria do DAAE-Araraquara. Neste, observa-se como tal Departamento pretende alinhar-se à estratégia do Consórcio, especialmente aos objetivos O1, O3, O6, O9 e O10. Em Souza (2007), também podem ser observados os demais scorecards, inclusive para os departamentos de Gerência Operacional, Recursos Humanos e Educação Ambiental.

\section{Conclusões}

De modo geral, considerou-se o Balanced Scorecard bastante aplicável e útil para os sistemas públicos, a exemplo da gestão de resíduos sólidos, analisada neste estudo. Também há boa aplicabilidade para modelos em que a alta gerência é constituída por mais de um gestor, todos com poderes de deliberação. Esta aplicabilidade é garantida, principalmente, pela utilização do mapeamento cognitivo, na estruturação do problema e busca do consenso entre as diferentes visões. Também é assegurada pela utilização dos temas e princípios da sustentabilidade como referências de topo, e do BSC como ferramenta para estruturação da estratégia. Desta forma, torna-se bastante viável e prático elucidar quais devem ser os objetivos estratégicos, a sua hierarquia, e quais as perspectivas estratégicas que os caracterizam. Também é importante observar que os princípios da sustentabilidade, por suas naturezas, já induzem um direcionamento tanto para as dimensões da sustentabilidade como para as perspectivas originais do BSC, o que permite uma visão estratégica integrada e bastante lógica e tangível, quando esclarecida em um mapa estratégico.

Os resultados principais obtidos neste estudo foram os objetivos estratégicos do Consórcio, e, consequentemente, o mapa estratégico e os scorecards gerais e dos departamentos. Demonstraram-se bastante coerentes com a problemática, e atenderam ao que se esperava, com relação à integração da sustentabilidade e o BSC. Apesar de traduzirem visões relativas a um caso específico, podem ser referências importantes para a elaboração de estratégias com este mesmo intuito, seja para efeito de comparação, como para serem integradas a elas, desde que correspondam a aspectos relevantes das visões dos gestores. A estratégia obtida neste estudo também pode ser mais amplamente detalhada, aproveitando os objetivos atuais e integrando-os a estes novos objetivos, de forma a descrever com maior riqueza outras possibilidades de direcionamento de uma estratégia para a gestão pública de resíduos.

Por fim, considera-se que este trabalho configura-se numa referência interessante para o meio acadêmico, na elaboração de pesquisas relacionadas ao tema, e para os sistemas públicos de resíduos brasileiros. Aos primeiros, recomenda-se o aprofundamento da pesquisa sobre a metodologia adotada, e sua aplicação em outros casos, como os outros sistemas públicos de saneamento, ou outros setores da administração pública. Aos gestores dos sistemas públicos de resíduos no Brasil, aconselha-se que tomem este material como referência para a tomada de decisões, para uma compreensão mais crítica de seus próprios sistemas e como estímulo para a elaboração de suas próprias estratégias para sustentabilidade dos serviços prestados e dos processos de gestão.

\section{Referências}

ACKERMAN, F.; EDEN, C.; CROPPER, S. Getting started with cognitive mapping. $7^{\text {th }}$ ed. University of Warwick: Young OR Conference, p. 1992. p. 65-82.

ANDREWS, K. R. The concept of corporate strategy. Homewood, IL: Richard D. Irwin, 1980.

ASSOCIAÇÃO NACIONAL DOS SERVIÇÕS MUNICIPAIS DE SANEAMENTO. Experiências de êxito em serviços municipais de saneamento. Brasília: ASSEMAE, 2006.

COMPROMISSO EMPRESARIAL PARA A RECICLAGEM. Pesquisa ciclosoft. CEMPRE, 2006. Disponível em: <www.cempre.org.br>. Acesso em: 30 jan. 2007.

HAMEL G.; PRAHALAD, C. K. Objetivo estratégico. Londres: Harvard Business Review, 1989.

INSTITUTO BRASILEIRO DE GEOGRAFIA E ESTATÍSTICA. Economia informal urbana. Rio de Janeiro: IBGE, 2003.

INSTITUTO BRASILEIRO DE GEOGRAFIA E ESTATÍSTICA. Indicadores de desenvolvimento sustentável. Rio de Janeiro: IBGE, 2004b.

INSTITUTO BRASILEIRO DE GEOGRAFIA E ESTATÍSTICA. Pesquisa da produção industrial. Rio de Janeiro: IBGE, 2004a.

INSTITUTO BRASILEIRO DE GEOGRAFIA E ESTATÍSTICA. Pesquisa nacional de saneamento básico. Rio de Janeiro: IBGE, 2000. 


\section{INSTITUTO BRASILEIRO DE GEOGRAFIA E} ESTATÍSTICA. Pesquisa nacional de orçamentos familiares. Rio de Janeiro: IBGE, 2002.

KAPLAN, R.; NORTON, D. P. The balanced scorecard. Boston: Harvard Business School Press, 1996.

KAPLAN, R; NORTON, D. P. A estratégia em ação: balanced scorecard. Boston: Harvard Business School Press, 1997.

KAPLAN, R; NORTON, D. P. Strategy maps: converting intagible assets into tangible outcomes. Boston: Harvard Business School Press, 2004.

MILANEZ, B. Resíduos sólidos e sustentabilidade: princípios, indicadores e instrumentos de ação. 2002. 207 f. Dissertação (Mestrado em Engenharia Urbana)Universidade Federal de São Carlos, São Carlos, 2002.

MINTZBERG, H. Five P's for strategy. California Management Review, 1987.
MONTEIRO, J. H. P. et al. Manual de gerenciamento integrado de resíduos sólidos. Rio de Janeiro: IBAM, 2001.

OLVE, N. G.; ROY, J.; WETTER, M. Performance Drivers: a practical guide to using the Balanced Scorecard. Chichester: John Wiley \& Sons, 1999.

ORGANIZAÇÃO DAS NAÇÕES UNIDAS. Indicators of sustainable development: guidelines and methodologies. Nova York: ONU, 2001.

QUINN, J. B. Strategies for change: logical incrementalism. Londres: Richard D. Irwin, 1980.

SLACK, N. Administração da produção. São Paulo: Atlas, 2002.

SOUZA, R. G. Gestão de resíduos sólidos: utilização do Balanced Scorecard. 2007. 159 f. Dissertação (Mestrado em Engenharia Urbana)-Universidade Federal de São Carlos, São Carlos, 2007.

TCHOBANOGLOUS, G. Integrated solid waste management: engineering principles and management issues. Nova York: McGraw-Hill, 1993. 